ISSN 0103-7013

Psicol. Argum., Curitiba, v. 28, n. 61, p. 159-166 abr./jun. 2010 Licenciado sob uma Licença Creative Commons

\title{
DISCUSSÃO DA EVOLUÇÃO DE UMA SÍNDROME AUTÍSTICA TRATADA EM TERMOS DE ESTRUTURAÇÃO PSÍQUICA E DE ACESSO À COMPLEXIDADE ${ }^{1}$
}

\author{
Discussion about the evolution of an autistic syndrome treated in terms of psychic \\ structuration and access to the complexity
}

\section{Graciela Cullere-Crespin}

Psicanalista membro da Association Lacanienne Internationale e do grupo francês afiliado à WAHIM (World Association for Infant Mental Health). Especializou-se em psicopatologia do bebê e da criança pequena, assim como no tratamento de síndromes autísticas, Université de Paris XIII, Paris, e-mail: graciela.cc@infonie.fr

\begin{abstract}
Resumo
A autora aborda o autismo como fracasso do circuito pulsional entre o bebê e aquele que faz função de Outro para ele, o que produz a ausência da apetência simbólica característica dos bebês com desenvolvimento padrão, ficando o bebê fechado em si mesmo, assim como seu Outro, extremamente perturbado, também se fecha ao contato com ele. Defende a ideia de que a proposta terapêutica depende da concepção do distúrbio. Assim, na abordagem comportamental, trata-se de fazer suplência aos déficits cognitivos, através de um treinamento específico, que reforça o fechamento da criança ao Outro; enquanto na abordagem psicanalítica se trata de apostar na criança como sujeito, na sua relação com o Outro. Propõe três etapas para o trabalho psicanalítico com crianças autistas: aproximação, engajamento e trocas, ilustrando com um caso clínico.
\end{abstract}

Palavras-chave: Autismo. Circuito pulsional. Outro. Tratamento psicanalítico.

1 Traduzido do original "Discussion de l'évolution d'um syndrome autistique traité em termes de structuration psychique et d'accès à la complexité”, publicado em: Cullere-Crespin, G. (Org.). Crespin, G. C. (Org.). (2008). Cahier de Preaut: Evaluations diagnostiques, évaluation des traitements de l'autisme (L. M. F. Bernardino, Trans.). Paris: l'Harmattan. 


\begin{abstract}
The author approaches the autism as a failure in the drive circuit between the baby and the one who play the role of the Other to him, that brings the absence of the symbolic appetence typical in babies with normal development. The baby stays closed in himself, just like his Other, extremely disturbed, also stays with no contact with him. The author defends that the therapeutic proposition depends on the conception of the trouble. So, the behaviorist approach proposes supplying the cognitive deficits through a specific training, increasing the closure of the child to the Other. The psychoanalytic approach proposes to bet in the child as a subject in its relationship with the Other. The author also proposes three steps to the psychoanalytic work with autistic children: approximation, engagement and exchanges, and illustrates this with a clinical case.
\end{abstract}

Keywords: Autism. Drive circuit. Other. Psychoanalytic treatment.

\section{O desenvolvimento normal}

O processo do desenvolvimento normal é frequentemente descrito como uma construção na qual o bebê, desde o nascimento, participa ativamente com a ajuda de sua apetência simbólica (Cullere-Crespin, 2007a), que o torna atento e desejante diante do que o outro - geralmente sua mamãe - transmite-lhe ao cuidar dele. Assim, a criança com desenvolvimento padrão, "aprende", "embebendo-se" literalmente com as características do Outro $^{2}$, por identificação e em seguida por imitação. Esse fenômeno é constante e maciço durante os primeiros anos de vida, e garante a emergência do bebê enquanto sujeito, enquanto sujeito capaz de se pensar ele mesmo.

A articulação pulsional, tal como a apreendemos em inúmeros trabalhos de M-C. Laznik (2003) sobre as pulsões é a cavilha mestra desse fenômeno, ao constituir literalmente uma "correia de transmissão" entre o sujeito e o Outro. Assim, essa articulação é a fonte da organização e do enriquecimento, por via circular e retroativa, alimentando o processo de co-construção (Golse, 2006) do sujeito e de seu outro da relação primordial. Poderíamos representar esse processo sob a forma do seguinte esquema (Figura 1):

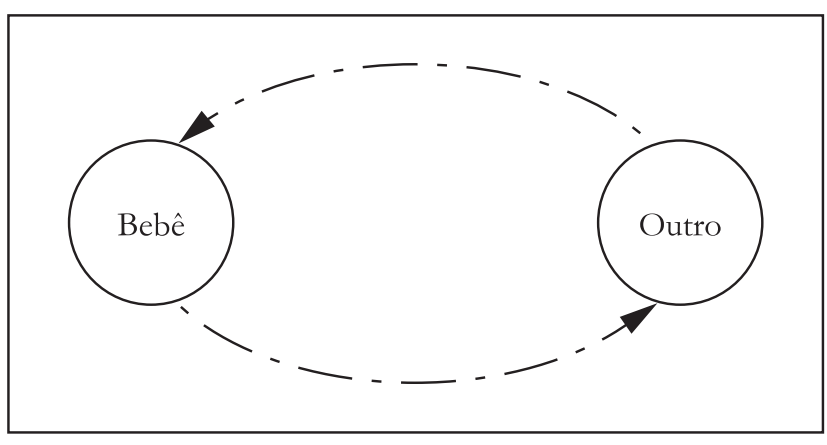

Figura 1 - Esquema da co-construção no desenvolvimento normal

As flechas representam os circuitos pulsionais do bebê, mas também da mãe, porque para que o fechamento do circuito se opere, é preciso que o bebê seja tomado enquanto objeto da pulsão da mãe, isto é, que o bebê seja satisfatório para ela, de que ele, em espelho, obtenha satisfação com isso, por sua vez. Esse esquema representa, pois, esse processo em que o bebê e a mãe são objetos de satisfação um para o outro, constituindo por isso essa ancoragem, esse enodamento dos dois campos, os quais, doravante entrelaçados, garantirão a reciprocidade necessária para o processo de comunicação, fonte de toda a transmissão e de todo o enriquecimento.

\footnotetext{
2 Entendemos aqui o Outro como o universo simbólico descrito por Lacan, que a mãe presentifica: "Ele encontra o Outro, não
} lhes digo como pessoa, ele encontra o Outro como tesouro do significante, como sede do código” (Lacan, 1973, p. 167). 


\section{Os distúrbios autísticos}

O que o processo autístico nos ensina, quando ele se enreda, e independentemente de sua etiologia, é que a articulação dos dois campos fracassa $^{3}$ e os circuitos pulsionais do sujeito e do Outro se fecham sobre si mesmos, cada qual em circuito fechado, ocasionando um processo inverso, a partir do qual não haverá mais uma construção comum, mas duas construções que se opõem:

a) do lado do bebê, observamos primeiramente um déficit das interações, que desemboca no curso do segundo ano de vida no aparecimento dos sintomas característicos das síndromes autísticas. O conjunto desses sintomas corresponde ao fato de que as aquisições da maturação neuromotora não são postas ao serviço da relação com o outro;

Assim:

b) A perseguição ocular, que permite ao sujeito dirigir seu olhar, culmina no evitamento ativo do rosto e dos olhos do outro, ao invés do "diálogo olho a olho", tão satisfatório no plano da comunicação e da afetividade, tanto para o outro quanto para a criança. As emissões sonoras, premissas da linguagem bem antes da fala, estão ausentes ou passam para jargões, ou até mesmo para a produção de palavras constituídas, mas sem endereçamento nem intencionalidade de troca;

c) A motricidade global, que culmina na marcha, afasta a criança dos outros, em função das deambulações incessantes, ao invés de aproximá-la delas;

d) A motricidade fina, que lhe permite manipular, culmina em movimentos estereotipados, ao invés da preensão palmar dos objetos de troca;

e) O conjunto das aquisições não se organiza em brincadeiras de imitação e em seguida em brincadeiras simbólicas, fontes de tantas aprendizagens para a criança normal;

f) Do lado do outro, observamos o que chamo de estados de extrema confusão (Cullere-Crespin, 2006), em que todas as competências relacionais e de comunicação são suspensas na relação com esta criança em particular, o pai ou a mãe conservando, além disso, intactas suas capacidades linguajeiras e de comunicação nas outras relações.

Poderíamos representar este processo pelo seguinte esquema (Figura 2):

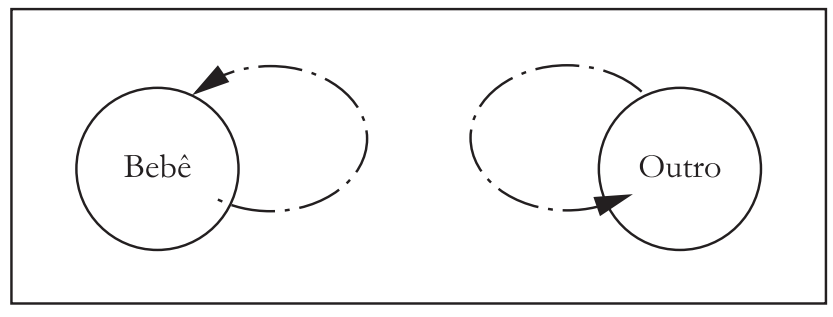

Figura 2 - Esquema do processo autístico

As flechas do circuito pulsional, voltadas cada qual em circuito fechado para seu campo próprio, representam esse processo de duplo desenvolvimento em autarquia um do outro, culminando uma no fechamento autístico e a outra no estado de extrema confusão.

Esse processo verifica, a contrario, o papel "civilizador" da articulação pulsional, em sua dimensão de transmissão, pois ela organiza o corpo e seu funcionamento, o comportamento e as representações do sujeito, em outras palavras, sua entrada no mundo simbólico e relacional.

É extremamente interessante observar que esse processo permanece o mesmo, quer a síndrome autística seja acompanhada de um déficit severo - o que é o mais frequente -, ou de capacidades cognitivas fora do comum, como nas síndromes de Asperger. Pois nesse último caso, essas capacidades excepcionais tampouco são postas ao serviço da relação com o Outro.

\footnotetext{
3 Hipótese fundamental da pesquisa Preaut, elaborada por M-C. Laznik (2006).
} 
Com efeito, tais capacidades podem se desenvolver de uma maneira exponencial, mas fora de contexto, não endereçadas, como a capacidade de Daniel Tammet para memorizar as 22.514 primeiras decimais do número Pi! (Tammet, 2007).

Mesmo se essa extraordinária competência foi secundariamente posta ao serviço de uma causa articulada com os outros - Daniel Tammet se serve dela para recolher fundos para tratar de crianças atingidas, como ele, de epilepsia infantil -, não deixa de ser verdadeiro que, com exceção do caso de ser pesquisador em matemática e por isso ser levado, com um objetivo preciso, a calcular tais números, uma competência dessas fica fora de sentido para o comum dos mortais, inclusive para o próprio Daniel Tammet.

Assim, a não instauração da ligação pulsional engaja muito cedo o sujeito em um desenvolvimento em autarquia que, de acréscimo, quer seja deficitário ou não, apresenta uma resistência ativa, perseverante em sua organização própria, como se esse fechamento em relação ao mundo dos outros tivesse uma função protetora para a criança. Essa organização autárquica permanece muito arredia a nossas tentativas de reconduzi-la a formas mais próximas do desenvolvimento da criança dita normal.

\section{As diferentes abordagens terapêuticas}

Daí se deduz que todo tratamento deste tipo de problemas se choca com um problema fundamental, que deve ser resolvido antes de poder avançar: é necessário fazer suplência à ausência de desejo - ou à incapacidade, ou à resistência - da criança para nos imitar e para buscar no mundo externo modelos identificatórios para seu próprio funcionamento? A organização mesma do distúrbio faz com que o acesso intersubjetivo à transmissão mesmo perturbado, como é o caso nas dificuldades clássicas de aprendizagem - é inacessível.

Assim, as diferentes abordagens elaboraram técnicas que correspondem à concepção que têm do distúrbio: as abordagens comportamentais, para as quais parece se tratar de um puro déficit irreversível, procedem por condicionamento operante para fazer suplência à ausência de desejo do sujeito para se conformar - ou a se opor, como na criança normal aos comportamentos cognitivos e sociais habituais.

A abordagem psicanalítica que preconizo, por sua vez, visa a suscitar, tanto quanto possível, a restauração da articulação pulsional, a fim de recolocar em funcionamento o "motor pulsional", de modo que a criança possa, com relação ao desenvolvimento normal, começar a se organizar, se construir e se enriquecer por meio identificatório e de imitação.

Poderíamos representar essas duas diferentes iniciativas no seguinte esquema (Figuras 3 e 4):

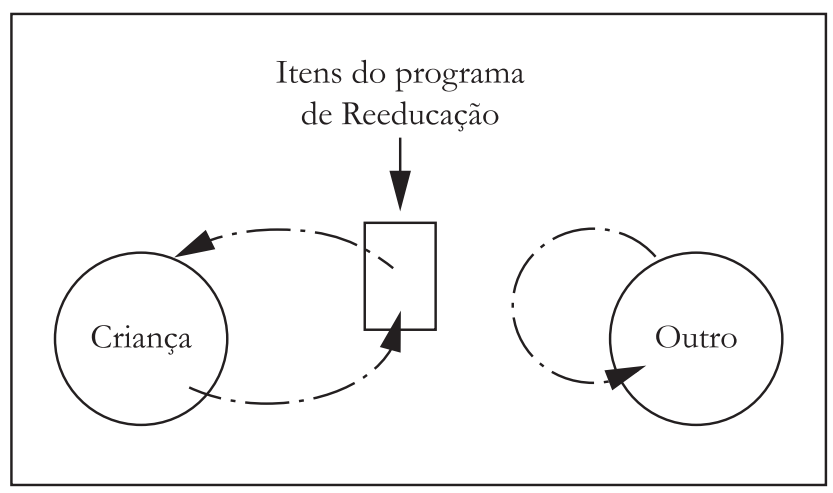

Figura 3 - Esquema da recuperação obtida por reeducação comportamental

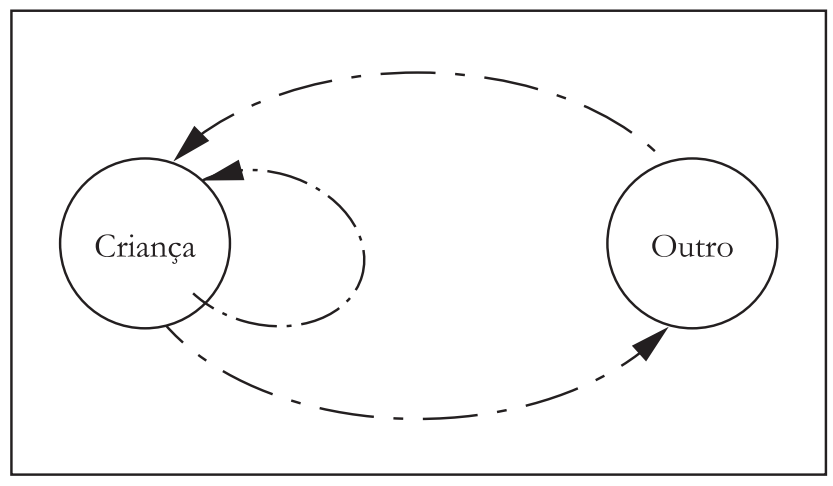

Figura 4 - Esquema da recuperação obtida pela abordagem subjetivante

Será que a espécie de "enxerto" que constitui a imposição de um comportamento obtido por condicionamento operante pode culminar em efeitos subjetivantes? Às vezes, sim, em casos favoráveis, mas então esses efeitos se produzem "de acréscimo", pois não são especificamente visados nesta abordagem.

Será que a "reanimação psíquica" (Laznik, 2005) que visa à abordagem analítica culmina em efeitos socializantes e de aprendizagem? Sim, nos casos favoráveis, pois permitem, além da construção psíquica, o acesso à complexificação, pela "via 
normal", isto é, a identificação e a imitação, como no desenvolvimento padrão.

É o que mostrarmos na sequência, com o auxílio do material clínico da evolução de uma criança.

\section{Da estruturação psíquica à complexificação}

Nas três etapas que descrevi da abordagem analítica dos distúrbios autísticos (Cullere-Crespin, 2007b), é interessante notar que as duas primeiras correspondem ao encontro, no sentido da articulação de dois mundos: o mundo autossensorial da criança autística e o mundo intersubjetivo do terapeuta, visando à construção psíquica da criança. E a terceira etapa, considerada como a última, corresponde à passagem da construção à complexificação. Com efeito, além da construção psíquica, que tem como resultado o acesso da criança a uma subjetividade própria, o processo torna-se cumulativo e conduz à complexidade.

A este título, pode-se considerar que o bebê que se apresenta bem, equipado com sua apetência simbólica (Cullere-Crespin, 2007a) desde o nascimento, chega de entrada à complexidade nas trocas.

\section{As três etapas da abordagem analítica das síndromes autísticas}

$\mathrm{Na}$ relação sensorial que a criança autista estabelece com o objeto não se trata, como no lactente com desenvolvimento normal, de um comportamento exploratório de descoberta de um objeto, como o descreve, por exemplo, Piaget no estádio sensório-motor. Com efeito, nesse estádio de sua evolução, a atividade sensorial do lactente, segundo Piaget, permite-lhe construir uma relação com um objeto que o funda em retorno como um sujeito, fazendo-o sair de um mundo centrado em torno "de algo que se ignora a si mesmo enquanto sujeito" (Piaget, 1937).

Na teorização piagetiana, a articulação que permite à criança franquear o estádio sensório-motor para o estádio em que ele se reconhece como sujeito é atribuída unicamente ao desenvolvimento cognitivo.

Do ponto de vista psicanalítico, esse franqueamento só pode se produzir na relação com o Outro, na medida em que o objeto - mesmo que seja nosso parceiro nas trocas - só existe para os humanos porque o outro no-lo designa como objeto do desejo. Esse desejo supõe o encontro com o outro e sua perda, isto é, sua presença e sua ausência, e a simbolização dessa, com o correlato acesso à falta que conduz ao desejo.

Assim, a sensação se torna percepção, a qual, nos humanos, corresponde ao acoplamento do funcionamento de um órgão sensorial com uma aparelhagem significante.

Apenas empregando esse caminho tortuoso é que os objetos do mundo se tornam objetos de investimento, dignos de interesse e de cobiça, e que eles abandonam seu estatuto de puro real, capazes apenas de sustentar uma experiência sensorial que permanece emparedada em si mesma. Portanto, a cognição, para nós, apoia-se na pulsão (Laznik, 2003), no investimento e na satisfação pulsional, e por isso está indissociavelmente articulada ao encontro do Outro.

\section{A etapa de aproximação}

Assim, na primeira etapa do processo analítico, trata-se de ir ao encontro da criança utilizando o registro sensorial que a criança por si mesma privilegia: deambulação, manipulações de objetos, tapinhas ou gritos. Não é de modo algum para ensinar-lhe algo ou para desviá-la disso, mas para introduzir-se aí, para forçar nossa entrada enquanto companheiro de brincadeiras, aceitando a atividade da criança como se ela nos fosse dirigida.

O terapeuta fará à criança o que a criança faz. a si mesma, introduzindo aí seu júbilo: ele mostrará à criança a que ponto ele está feliz de provocar-lhe esta satisfação que ele se provoca sozinho.

Mesmo que essa introdução seja apenas pura efração, que num primeiro tempo reproduzirá todo evitamento, a criança vai se achar tomada em um circuito que a partir de então inclui o Outro, seu júbilo e seu desejo, pois o terapeuta pode parar de fazer-lhe sua estimulação, para perguntar se ela a quer de novo.

Bem entendido, essa manobra pode durar às vezes um tempo muito longo antes de esboçar na criança uma relação verdadeiramente articulada ao júbilo e ao desejo do Outro, a criança autista perseverando ativamente em sua busca de satisfação autossensorial imediata. É quando o terapeuta terá necessidade de autossustentação, para não afundar 
na extrema confusão e abandonar suas tentativas de entrar em contato verdadeiro com a criança.

\section{Maxence}

Nos primeiros tempos de seu tratamento, Maxence, 3 anos, era muito dispersivo e deambulava, tocando em tudo e não se interessando por nada. Sentado, ele batia seus pés fazendo muito barulho. Sentada na sua frente, comecei a bater por minha vez. Pouco depois, introduzi nas batidas um ritmo, o que muito rapidamente interessou Maxence, que prestou muita atenção. Batidas ritmadas ocuparam longamente muitas de nossas sessões no início do tratamento. Em seguida, introduzi turnos de papéis: ele batia, eu batia, e parava. Produzia-se então um silêncio, durante o qual eu o olhava intensamente, sem uma palavra, mas com uma mímica de expectativa divertida. Se ele batia de novo, o jogo recomeçava, depois eu o interrompia novamente, deixava-lhe a iniciativa da brincadeira. Enfim, eu o surpreendi repetindo a brincadeira quando ele não estava esperando. Rapidamente, chegamos a uma algazarra alegre e barulhenta, que durava sessões inteiras, e que constituíram o primeiro verdadeiro encontro entre mim e Maxence.

\section{A etapa de engajamento}

Se formos suficientemente perseverantes como terapeutas, a criança começará a enviar sinais de reconhecimento de nossa presença, a partir dos quais mudaremos de posição: ao invés de estarmos na efração de seu circuito, nos colocaremos na posição de questionadores de sua posição desejante recém-adquirida. É o que caracteriza a entrada no engajamento: a satisfação não lhe vem mais de uma autoestimulação sensorial, mas do Outro, e a esse título pode vir a faltar.

As condições necessárias para o surgimento de um desejo e, portanto, de uma demanda dirigida, estão reunidas e o terapeuta trabalhará assiduamente para reproduzir as situações em que a criança poderá atravessar inúmeras vezes essa experiência.

Quando a experiência do encontro e da perda se produz, a criança - e o conjunto do entorno, inclusive o terapeuta! - devem enfrentar às vezes verdadeiros cataclismos, que podem nos fazer acreditar que a criança vai de mal a pior. Não se trata disso, e se soubermos administrar essa passagem delicada como o que ela é - a inscrição desta perda original que nos humaniza a todos -, impondo-nos ao mesmo tempo a falta, mas abrindo-nos à via do desejo, a criança a atravessará e poderá ter acesso a uma relação desejante, não apenas com o outro, mas com os objetos, que se tornarão objetos de investimento e não mais puros reais.

\section{Maxence}

Após aquele primeiro encontro barulhento, rítmico e motor, as ocasiões para fazer Maxence atravessar as experiências de conceber um desejo não deixarão de se apresentar: Maxence se coloca cada vez mais e começa a se interessar mais de perto por tudo o que se oferece a ele na peça, como descoberta e exploração. Inicialmente, de maneira fugaz e pouco organizada, seu interesse por objetos e brinquedos comuns se afirma pouco a pouco. Assim, rapidamente abordamos a necessidade de canalizar sua atividade, e as primeiras proibições fizeram seu aparecimento. Com esses primeiros limites fizemos a experiência de sua absoluta intolerância à frustração: crises de cólera cada vez mais espetaculares fizeram sua aparição. Violento, ele quebrava tudo, atacava o setting e o corpo da terapeuta, jogando-se no chão e gritando bem forte.

Ele seguiu um período muito delicado, em que pais e professores tiveram que ser especificamente apoiados pela terapeuta e pelo orientador, pois o comportamento de Maxence tinha se tornado muito violento e destrutivo. Todo o mundo pensava que Maxence regredira e que estava cada vez pior. Foi um verdadeiro trabalho convencer a todos a terem paciência e, ao mesmo tempo, permanecerem muito firmes quanto aos limites dados a Maxence. Sua irmã mais velha, que não compartilhava da estupefação e da angústia dos pais, foi de grande ajuda: ela não se intimidava; se era proibido para ela, ela não via nenhuma razão para que não o fosse para Maxence. Durante todo um período, a única pessoa capaz de "se manter firme" com Maxence foi sua irmã mais velha.

Por meu lado, a privação real que representava para Maxence o fato de eu interromper a sessão, na qual ele apreciava tanto o espaço de brincadeiras, foi a resposta que opus ao seu exercício de onipotência: desde que ele bloqueava e iniciava uma crise 
de cólera, eu parava tudo e o carregava literalmente para fora da peça, de tal modo ele se recusava a sair.

Durante vários meses as sessões acabavam rapidamente, de modo que tive de contar com a compreensão e a tolerância dos pais, que aceitaram que esse era o único modo de acabar com as crises de cólera de Maxence. Eu os apoiava, assim como aos professores, na ideia de que se tratava, com os meios físicos de uma criança de 4 anos, da famosa "crise de oposição" clássica das crianças de 18 meses.

Algumas semanas mais tarde, quando eu acabara de interromper a sessão e de combinar com sua mãe a próxima consulta, vejo pelo canto do olho Maxence se levantar e juntar os lápis que espalhara pelo chão, motivo da interrupção da sessão. Digo-lhe: "Viu só? Era o que tinha que fazer!" e Maxence se joga em meus braços, sob o olhar emocionado da mãe.

O aparecimento da ambivalência marca uma virada no tratamento, pois a partir de então a criança estava capturada nas trocas e na reciprocidade ${ }^{4}$.

\section{A entrada nas trocas}

O que caracteriza doravante a terceira etapa é a capacidade da criança de entrar nas trocas. Eu a considero como a última, pois, do ponto de vista de sua estruturação psíquica, a criança possui a partir de então as ferramentas requeridas para entrar em relação intersubjetiva com o mundo. É a partir desse momento que me parece possível dizer que se abandonou o tempo da construção para entrar no tempo da complexificação ${ }^{5}$.

Com efeito, é absolutamente notável que, quando se consegue colocar novamente em curso o processo de desenvolvimento, este se desenrola na mesma ordem que para a criança de desenvolvimento padrão e procede da mesma fonte: a criança aprende através da identificação e da imitação.

É para nós um trunfo, se posso dizer assim, que essa recuperação operada pela terapia analítica restabeleça um processo - nos limites do possível, e segundo as capacidades de cada criança - que é justamente aquele que falhou no início da vida.

Embora as crianças assim recuperadas permaneçam marcadas - às vezes severamente - pelo atraso adquirido e/ou pelas "bizarrices" próprias de sua organização anterior, sempre presentes sob forma residual e prontas para ressurgir em caso de "perigo interno", elas têm, contudo, acesso a um verdadeiro lugar de sujeito de seu desejo, capazes de expressá-lo e de sustentá-lo, bem como de ouvir/entender um limite para sua onipotência ou seu "gozo onipotente"!

E quando então lhes propomos espaços reeducativos específicos, elas têm acesso às aprendizagens guiadas pelo interesse e sustentadas por seu desejo, com os contratempos e impasses que isso implica, como constatamos nas dificuldades de aprendizagem comuns nas crianças recém-chegadas em geral.

\section{REFERÊNCIAS}

Cullere-Crespin, G. (2006). Le mythe des origines de l'autisme. In C. Preaut. Autismes: Etat de lieux du soin (pp. 63-69). Paris: l'Harmattan.

Cullere-Crespin, G. (2007a). L'epopée symbolique du nouveau-né. Paris: Erès.

Cullere-Crespin, G. (2007b). Deux ans de thérapie analytique d'un enfant autiste - discussion de l'approche et des résultats. In C. Preaut. Actualités du soin: Approches cognitivo-comportamentales et analytiques des troubles autistiques (pp. 44-90). Paris: l'Harmattan.

Cullere-Crespin, G. (Org.). (2008). Cahier de Preaut: Evaluations diagnostiques, évaluation des traitements de l'autisme (L. M. F. Bernardino, Trans.). Paris: l'Harmattan.

Golse, B. (2006). L’être bébé. Paris: PUF.

Lacan, J. (1973). Séminaire V: Les formations de l'inconscient. Paris: Le Seuil.

4 Para um relato detalhado dos progressos de Maxence, ver Cullere-Crespin (2007b, p. 87-88), em particular a "Discussão dos resultados: o caminho percorrido em termos de referências psicanalíticas".

5 Sem dúvida, era o que queria expressar Marie-Christine Laznik, há cerca de dez anos, quando dizia que "a psicanálise aplicada às crianças autistas era uma psicanálise ao inverso: nós as deixamos freqüentemente no ponto em que habitualmente as outras iniciam uma análise!". 
Laznik, M-C. (2003). Le bébé et la pulsion. Revue de Psychiatrie Française, 34(3), 14-28.

Laznik, M-C. (2005). Sidération et lumière, la voix dans le traitement d'un enfant de quatre mois. In C. Preaut. Psychanalyse et neurosciences face à la clinique de l'autisme et du bébé, sob a direção de G. Crespin (pp. 129-142). Paris: l'Harmattan.

Laznik, M-C. (2006). Preaut: Entre clinique et recherche. Revue Contraste, (25), 425.

Piaget, J. (1937). La construction du réel chez l'enfant. Neuchatel: Delachaux e Niestlé.

Tammet, D. (2007). Je suis né um jour bleu. Paris: Les Arènes.

Recebido: 14/03/2009

Received: 03/14/2009

Aprovado: 06/05/2009

Approved: 05/06/2009 